\title{
Study on FDI Entry Modes for Chinese Real Estate Industry
}

\author{
Huang Hui
}

School of Economics, Wuhan University of Technology, Wuhan, Hubei, China (278905488@qq.com)

\begin{abstract}
Combining the status quo of real estate in China and the need for enterprise's development, this text standing the foundation on the real estate industry's characteristics, using the grey situation decision analytical method for researching the choice tendency of estate enterprise's entry mode while entering international market.
\end{abstract}

Key words - Chinese Real Estate Industry, Foreign Direct Investment, Entry Mode

\section{中国房地产业 FDI 进入模式研究}

\author{
黄慧 \\ 武汉理工大学经济学院, 武汉, 湖北, 中国
}

\begin{abstract}
摘 要 结合目前中国国内房地产的现状和企业的发展需求, 本文站在房地产业自身特点的基础上运用灰局势决策分析方法对房 地产企业海外投资进入模式倾向决策进行分析，为房地产企业进入国际市场的进入模式的选择提供参考。
\end{abstract}

关键词 房地产业, 对外直接投资, 进入模式, 灰局势决策

\section{1. 引言}

自 2003 年国务院明确将房地产业作为国民经济的支 柱产业, 国内房地产业蓬勃发展。然而由于种种因素, 房 地产业的发展偏离了持续健康的发展道路, 造成房价虚高 的状况。对此, 中央及地方政府不断出台各项财政与货币 政策对房地产业进行打压。在过去的一年内 40 多个城市实 施限购, 600 多个城市出台房价控制目标。这一做法使得 全国各地商品住房成交量急剧下跌, 房地产企业此时需要 承受比以前更大的土地资源和银行信贷的压力以及经营风 险。这种国内市场的压力与国外市场的发展状况吸引了众 多房地产企业试水海外, 寻求其新的发展。而此时对外直 接投资进入模式选择是企业跨国经营研究的关键。

\section{2. 对外直接投资进入模式分类}

房地产业具有许多不同于制造业的特征, 其中最为重 要的一点就是房地产业是包括房地产开发经营、物业管理、 和房产服务等等在内的第三产业, 它的生产和消费的不可 分离。这就造成房地产企业 FDI 进入模式的分类不可能采 取制造业的一般出口模式和契约模式。

按照国际直接投资的手段与房地产业的特征, 房地产 业FDI 市场进入模式有以下几种: 并购, 又称并购投资, 是
对目标国企业的兼并与收购的合称; 新建, 又称为绿地投 资, 指投资者在东道国新建设立企业。新建投资又可按照 出资比分为独资、合资经营 (股权 $50 \%$ 以上) 和合资经营 (股权 $50 \%$ 以下)。

\section{3. 房地产企业对外直接投资进入模式倾向选择的实 证分析}

结合 “跨国并购、独资、合资股权大于或等于 $50 \%$ 、 合资股权小于 $50 \%$ ” 这四种进入模式的特点, 企业如何选 择更有倾向的进入模式呢? 这需要通过定量分析予以验 证。运用灰局势决策效果测度的系统方法可以充分地考虑 房地产业 FDI 进入模式的各特性的目标极值, 系统分析不 同进入模式的综合效果, 从而得出房地产业 FDI 进入模式 的决策倾向。

\section{1 灰局势决策的效果测度计算步骤}

步骤一: 将 FDI 进入模式分为独资、合资（股权低于 $50 \%$ ）、合资（股权高于 50\%）和并购四种类型。每一种类 型在资源投入水平、控制力、风险程度等等方面都存在差 异, 经过篮选选定资源投入 $(\alpha)$ 、控制力 $(\beta)$ 、风险程 
度 $(\mathrm{y})$ 、资金回报周期 $(\delta)$ 、灵活性 $(\varepsilon)$ 五项指标作 为预期效应参数。

令房地产业 FDI 进入模式决策为事件 A, 选择进入模式 的方案 $\mathrm{B}=\left\{b_{1}, b_{2}, \ldots b_{j}\right\}$ 为对策, 则有局势 $S_{n}$ :
$S_{1}=\left(a, b_{1}\right), S_{2}=\left(a, b_{2}\right), S_{3}=\left(a, b_{3}\right), S_{4}=\left(a, b_{4}\right)$

下面采用五尺度法请专家对每种对策的内在特性指标 打分, 如下表 1 。

表 1 五尺度法专家打分表

\begin{tabular}{|c|c|c|c|c|c|c|}
\hline \multirow{2}{*}{ 进入模式 } & \multicolumn{5}{|c|}{ 特性指标 (专家打分 五尺度法) } \\
\cline { 2 - 7 } & 资源投入 $\alpha$ & 控制力 $\beta$ & 风险程度 $\gamma$ & 资金回报周期 $\delta$ & 灵活性 $\varepsilon$ & 投资回报率 $\eta$ \\
\hline 模式 1 $\left(b_{1}\right)$ 并购 & 4 & 4 & 1 & 1 & 5 & 4 \\
\hline 模式 2 $\left(b_{2}\right)$ 合资 (股权抵于 $\left.50 \%\right)$ & 1 & 1 & 3 & 3 & 3 & 1 \\
\hline 模式 3 $\left(b_{3}\right)$ 合资 $($ 股权高于 $50 \%)$ & 3 & 3 & 4 & 4 & 2 & 3 \\
\hline 模式 4 $\left(b_{4}\right)$ 独资 & 5 & 5 & 5 & 5 & 1 & 5 \\
\hline
\end{tabular}

步骤二：确定目标 P ( $P=1,2,3,4,5)$ 及其极性。

预期效应 1：资源投入（ $\alpha)$ ，极小值极性;

预期效应 2：控制力（ $\beta$ ），极大值极性;

预期效应 3: 风险程度 ( $\mathrm{Y}$ ), 极小值极性;

预期效应 4：资金回报周期（ $\delta ） ，$ 极小值极性;

预期效应 5: 灵活性（ $\varepsilon$ ）, 极大值极性;

预期效应 6 : 投资回报率 $(\eta)$ ), 极大值极性。

步骤三: 在各局势样本下作效果测度变换

(1)对于预期效应 1 资源投入（ $\alpha$ ), 极小值极性:

$b_{1}, \alpha: U_{1}^{1}=4 ; \quad b_{2}, \alpha: U_{2}^{1}=1 ; b_{3}, \alpha: U_{3}^{1}=3 ; b_{4}, \alpha: U_{4}^{1}=5$

经过极小值预期转换, 有 $r_{j}^{1}=\frac{\min _{j} U_{j}^{1}}{U_{j}^{1}}, j=1,2,3,4$

而 $\min _{j} U_{j}^{1}=\min \left\{U_{1}^{1}, U_{2}^{1}, U_{3}^{1}, U_{4}^{1}\right\}=\min \{4,1,3,5\}=1$

则有 $r_{j}^{1}=\frac{\min _{j} U_{j}^{1}}{U_{j}^{1}}=\frac{1}{U_{J}^{1}}$,

则对于 $b_{1}$, 有: $r_{1}^{1}=\frac{1}{U_{1}^{1}}=\frac{1}{4}=0.25, r_{2}^{1}=\frac{1}{U_{2}^{1}}=\frac{1}{1}=1$,

$r_{3}^{1}=\frac{1}{U_{3}^{1}}=\frac{1}{3}=0.33, \quad r_{4}^{1}=\frac{1}{U_{4}^{1}}=\frac{1}{5}=0.2$

(2)对于预期效应 2 控制力（ $\beta$ ), 极大值极性:

$$
U_{1}^{2}=4, \quad U_{2}^{2}=1, \quad U_{3}^{2}=3, \quad U_{4}^{2}=5
$$

经过极大值预期转换，有

$r_{j}^{2}=\frac{U_{j}^{2}}{\max _{j} U_{J}^{2}}, \quad j=1,2,3,4$

而 $\max _{j} U_{J}^{2}=\max \left\{U_{1}^{2}, U_{2}^{2}, U_{3}^{2}, U_{4}^{2}\right\}=\max \{4,1,3,5\}=5$

则有 $r_{j}^{2}=\frac{U_{j}^{2}}{\max _{j} U_{J}^{2}}=\frac{U_{J}^{2}}{5}$,

则对于 $b_{2}$, 有: $r_{i}^{2}=\frac{4}{5}=0.8, r_{2}^{2}=\frac{1}{5}=0.2, r_{3}^{2}=\frac{3}{5}=0.6$,

$r_{4}^{2}=\frac{5}{5}=1$

(3)对于预期效应 3 风险程度（Y ），极小值极性：

如上推算, 则有: $r_{1}^{3}=1, r_{2}^{3}=0.33, r_{3}^{3}=0.25, r_{4}^{3}=0.2$

(4)对于预期效应 4 资金回报周期（ $\delta)$ ，极小值极性:

有: $r_{1}^{4}=1, r_{2}^{4}=0.33, r_{3}^{4}=0.25, r_{4}^{4}=0.2$

(5)对于预期效应 5 灵活性（ $\varepsilon$ ), 极大值极性:

有: $r_{1}^{5}=1, r_{2}^{5}=0.6, r_{3}^{5}=0.4, r_{4}^{5}=0.2$

(6)对于预期效应 6 投资回报率 $(\eta)$ ), 极大值极性:

有: $r_{1}^{6}=0.8, r_{2}^{6}=0.2, r_{3}^{6}=0.6, r_{4}^{6}=1$

步骤四: 建议统一效果测度空间

$r_{j}^{\varepsilon}=\frac{1}{6} \sum_{p=1}^{6} r_{j}^{p}, \quad j=1,2,3,4$,

于是有:

局势 $S_{1}=\left(a, b_{1}\right), r_{1}^{\varepsilon}=\frac{1}{6}(0.25+0.8+1+1+1+0.8)=0.81 ＼mathrm{~ ； ~}$

局势 $S_{2}=\left(a, b_{2}\right), r_{2}^{\varepsilon}=\frac{1}{6}(1+0.2+0.33+0.33+0.6+0.2)=0.443 ＼mathrm{~ ； ~}$

局势 $S_{3}=\left(a, b_{3}\right), r_{3}^{\varepsilon}=\frac{1}{6}(0.33+0.6+0.25+0.25+0.4+0.6)=0.405$ ；

局势 $S_{4}=\left(a, b_{4}\right), r_{4}^{\varepsilon}=\frac{1}{6}(0.2+1+0.2+0.2+0.2+1)=0.467$. 
步骤五：确定满意局势

$$
\begin{aligned}
& \because r_{j^{*}}^{\varepsilon}=\max r_{j}^{\varepsilon}=\max \left\{r_{1}^{\varepsilon}, r_{2}^{\varepsilon}, r_{3}^{\varepsilon}, r_{4}^{\varepsilon}\right\} \\
& =\max \{0.81,0.443,0.405,0.467\}=0.81=r_{1}^{\varepsilon}
\end{aligned}
$$

则由此可见, 在平等地对待各种特性预期效应指标的 基础上效果测度评价的结果是: 跨国并购模式为最优决策 方案, 独资经营方案次之 $\left(r_{4}^{\varepsilon}=0.467\right)$ 。

此测度结果说明在均衡各预期效应的情况下, 房地产 业对外直接投资进入模式偏重于选择控制力更高的进入模 式。然而当企业对各种预期效应的重视程度存在偏差时, 我们需要加入对预期效应的权重来进行进入模式的决策。

\section{2 考虑权重的进入模式决策倾向}

对进入模式预期效应指标 (资源投入、控制力、风险程 度、资金回报周期、灵活性和投资回报率）的倚重程度采 取五分制打分, 结果如下:

\begin{tabular}{|c|c|c|c|c|c|c|}
\hline & $\begin{array}{c}\text { 资源投 } \\
\lambda \alpha\end{array}$ & $\begin{array}{c}\text { 控制力 } \\
\beta\end{array}$ & $\begin{array}{c}\text { 风险程 } \\
\text { 度 } \gamma\end{array}$ & $\begin{array}{c}\text { 资金回报 } \\
\text { 周期 } \delta\end{array}$ & $\begin{array}{c}\text { 灵活性 } \\
\theta\end{array}$ & $\begin{array}{c}\text { 投资回 } \\
\text { 报率 } \eta\end{array}$ \\
\hline 倚重程度 & $\mathrm{a}$ & $\mathrm{b}$ & $\mathrm{c}$ & $\mathrm{d}$ & $\mathrm{e}$ & $\mathrm{f}$ \\
\hline
\end{tabular}

则我们可以认为: A 公司跨过经营决策中对资源投入 （ $\alpha$ ) 的倚重程度为 $a / 21$; 对控制力 ( $\beta$ ) 的倚重程度为 $\mathrm{b} / 21$; 对风险程度 $(\boldsymbol{Y})$ 的倚重程度为 $c / 21$; 对资金回报 周期 $(\delta)$ 的倚重程度为 $\mathrm{d} / 21$; 对灵活性 $(\theta)$ 的倚重程 度为 $e / 21$; 对投资回报周期 $(\eta)$ 的倚重程度为 $f / 21$. 于 是, 表 1 演变成为:

\begin{tabular}{|c|c|c|c|c|c|c|}
\hline \multirow{2}{*}{$\begin{array}{c}\text { 进入 } \\
\text { 模式 }\end{array}$} & $\begin{array}{c}\text { 资源投入 } \\
\alpha \times \\
(\mathrm{a} / 21)\end{array}$ & $\begin{array}{c}\text { 控制力 } \\
\beta \times \\
(\mathrm{b} / 21)\end{array}$ & $\begin{array}{c}\text { 风险程度 } \\
\gamma \times \\
(\mathrm{c} / 21)\end{array}$ & $\begin{array}{c}\text { 资金回报 } \\
\text { 周期 } \delta \times \\
(\mathrm{d} / 21)\end{array}$ & $\begin{array}{c}\text { 灵活性 } \\
\varepsilon^{\times} \\
(\mathrm{e} / 21)\end{array}$ & $\begin{array}{c}\text { 投资回报 } \\
\text { 率 } \eta \times \\
(\mathrm{f} / 21)\end{array}$ \\
\hline $\mathrm{B}_{1}$ & 4 & 4 & 1 & 1 & 5 & 4 \\
\hline $\mathrm{B}_{2}$ & 1 & 1 & 3 & 3 & 3 & 1 \\
\hline $\mathrm{B}_{3}$ & 3 & 3 & 4 & 4 & 2 & 3 \\
\hline $\mathrm{B}_{4}$ & 5 & 5 & 5 & 5 & 1 & 5 \\
\hline
\end{tabular}

则, 上式步骤四演变为:

步骤四*: 建立统一效果测度空间

$r_{j}^{\varepsilon}=\frac{1}{5} \sum_{p=1}^{5} r_{j}^{p}, \quad j=1,2,3,4$,
于是有：局势 $S_{1}=\left(a, b_{1}\right)$,

$$
\begin{aligned}
r_{1}^{\varepsilon^{*}}= & \frac{1}{6}\left(0.25 \bullet \frac{a}{21}+0.8 \bullet \frac{b}{21}+1 \bullet \frac{c}{21}+1 \bullet \frac{d}{21}+1 \bullet \frac{e}{21}+0.8 \bullet \frac{f}{21}\right) \\
= & 0.002 a+0.0063 b+0.0079 c \\
& +0.0079 d+0.0079 e+0.0063 f \\
= & \sum
\end{aligned}
$$

局势 $S_{2}=\left(a, b_{2}\right)$,

$$
\begin{aligned}
r_{2}^{\varepsilon *}= & \frac{1}{6}\left(\frac{a}{21}+0.2 \bullet \frac{b}{21}+0.33 \bullet \frac{c}{21}+0.33 \bullet \frac{d}{21}+0.6 \bullet \frac{e}{21}+0.2 \bullet \frac{f}{21}\right) \\
= & 0.0079 a+0.0016 b+0.0026 c \\
& +0.0026 d+0.0048 e+0.0016 f \\
= & \Phi
\end{aligned}
$$

局势 $S_{3}=\left(a, b_{3}\right)$,

$$
\begin{aligned}
r_{3}^{\varepsilon^{*}}= & 0.0037 a+0.0067 b+0.0028 c \\
& +0.0028 d+0.0044 e+0.0067 f \\
= & \Psi
\end{aligned}
$$

局势 $S_{4}=\left(a, b_{4}\right)$,

$$
\begin{aligned}
r_{4}^{\varepsilon *}= & 0.0022 a+0.011 b+0.0022 c \\
& +0.0022 d+0.0022 e+0.011 f \\
= & \Omega
\end{aligned}
$$

则满意局势为 $S_{j}^{*}=\left(a, b_{j}\right), r_{j *}^{i}=\max \left\{r_{j}^{i *}\right\}=\max \{\Sigma$, $\Phi, \Psi, \Omega\}$

此时房地产企业可以根据在对外投资过程中所面临的 不同情况来权衡对进入模式预期效应的倚重, 从而选择出 更优的对外直接投资进入模式。

\section{4. 结语}

各种进入模式的特性决定了房地产业对跨国经营的不 同预期, 而房地产业 FDI 进入模式的选择受到市场战略因 素、东道国因素以及企业自身因素的影响, 这三大类因素 的相互作用造成企业对进入国际市场预期效应的不同，从 而对进入模式的选择造成不同程度的影响。因此对于房地 产跨国公司来说最佳的进入模式是将所有的相关因素进行 权衡后能够最大化企业长期利益的选择。 


\section{参考文献(References)}

[1] Zheng Changjuan, Xu Jianzhong. An Empirical Test of Foreign Service Firms' Entry Mode Choice in China. International Trade Journal, 2005.01.

[2] Sun Xiaohua. Foreign $M \& A$ Situation and Inspiration in Developing Countries. International Economic Cooperation. 2004.12. p28-32.

[3] Wang Yimin. Theoretical Analysis on Service Enterprises
Overseas Market Entry Mode Selection. International Trade Journal. 2002.12.

[4] Yan Daying. On the Determinants for the Chinese Firms' FDI Entry Mode Choice_Empirical Analysis of Acquisitions and Joint Ventures. Journal of Shanxi Finance and Economics University. 2008.10.

[5] Luo Y D, R L Tung. International Expansion of Emerging Market Enterprises: A Springboard Perspective. Journal of International Business Studies.2007, 38(4):481-498. 